\title{
ADVANCED HIGH STRENGTH STEEL (AHSS) ALLOYS
}

\author{
Mariana Lucaci $^{1^{*}}$, Magdalena Lungu ${ }^{1}$, Eugeniu Vasile ${ }^{2}$, Virgil \\ Marinescu $^{1}$, Dorinel Talpeanu ${ }^{1}$, Gabriela Sbarcea ${ }^{1}$, Nicolae Stancu ${ }^{1}$, Ion \\ Ivan$^{1}$, Iorga Alexandru ${ }^{1}$, Manta Eugen ${ }^{1}$, Mihai Marin ${ }^{1}$, Diana Cirstea ${ }^{1}$, \\ Ioana Ion ${ }^{1}$ \\ ${ }^{1}$ National Institute for Research and Development in Electrical Engineering \\ ICPE-CA (INCDIE ICPE-CA), Splaiul Unirii 313, sector 3, Bucharest, \\ Romania. \\ ${ }^{2}$ University "Politehnica" of Bucharest (UPB), Splaiul Independentei 313, \\ sector 6, Bucharest, Romania. \\ *mariana.lucaci@icpe-ca.ro
}

\section{Introduction}

Over the last decades, there has been a strong competition between ferrous versus non-ferrous metallurgical industries in the production of low density alloys, as a result of increasing end-user demands for high-performance and cost effective materials for structural applications, which have also additional safety requirements in operation [1-5]. The answer of the steel industry producers to these requirements was to develop a new class of Advanced High Strength Steel (AHSS). The main advantages of the AHSS class are the high deformability and impact resistance compared to the high strength steels currently in use [1]. If the conventional high strength steels own their properties to the hardening of solid solution, precipitating of some hardening phases or refining of grain size, the AHSS alloys are hardened by phase transformations and develop nanocrystalline structures that may contain different types of phases, depending on their chemical composition, processing and the chosen thermal and thermomechanical treatment parameters [59].

The properties of these materials are determined by the nanocrystalline structure and by the possibilities of finishing the nanostructure by thermal and thermo-mechanical treatments. In fact, these materials can be considered as ironbased metal matrix nanocomposite materials. It is clear that the production technologies involve rapid processing techniques followed by proper thermal and thermo-mechanical treatments that lead to the production of materials with specific properties. In this paper, the research on obtaining AHSS materials using spark plasma sintering process (SPS) and induction melting cooper mold casting (IM-CuMC) techniques is presented. SPS technique is based on the simultaneous application of pressure and pulsed electrical current for a short period of time during the densification process in order to obtain dense sintered compacts at temperatures lower than those used in classical sintering processes, while maintaining a minimum growth of the grain size and preserving the refinement of the microstructure [10]. The IMCuMC technique is a rapidly solidified technique which avoids segregation of the constitutive elements and the grain size growth during cooling.

\section{Experimental Procedure}

The AHSS alloys with the chemical composition presented in table 1 were obtained by spark plasma sintering (SPS) and induction melting cooper mold casting (IM-CuMC) techniques. For the SPS process, alloyed powders were used, which were obtained from a melt spun strip (Figure. 1a) by the melt spinning according to our method presented elsewhere [11]. The strip was mechanically milled using a planetary ball milling system. The average particle 
diameter of the powders was $125 \mu \mathrm{m}$. The sintering was performed using a HPD 25 - FCT Systeme spark plasma sintering equipment. The sintering cycle consisted in sintering at $1050 \mathrm{oC}$ and $1100 \mathrm{oC}$ and a dwell time of 10 minutes, followed by controlled cooling with a cooling rate of 50-75 oC/min of a desired amount of alloyed powder, in order to obtain cylindrical shaped samples with $20 \mathrm{~mm}$ in diameter and about $4 \mathrm{~mm}$ in height, (Figure. 1b). During sintering, a pressure of $40 \mathrm{MPa}$ was applied. After die extraction, the samples were mechanically processed to remove the graphite foils and to obtain a roughness $\mathrm{Ra}$ of the sample surface in the range of $0.06-0.14 \mu \mathrm{m}$.

\begin{tabular}{|l|l|l|l|l|l|l|}
\hline \multirow{2}{*}{$\begin{array}{l}\text { Type } \\
\text { of } \\
\text { Alloy }\end{array}$} & \multicolumn{6}{|l|}{ Chemical composition, wt $\%$} \\
\cline { 2 - 7 } & Fe & $\mathrm{Cr}$ & $\mathrm{Ni}$ & $\mathrm{Zr}$ & $\mathrm{B}$ & $\mathrm{Si}$ \\
\hline AHS & 68.0 & 10.9 & 6.8 & 10.4 & 2.0 & 1.6 \\
S & 7 & 2 & 9 & 5 & 6 & 1 \\
\hline
\end{tabular}

Table 1. The chemical composition of the synthesized AHSS materials, (wt \%)

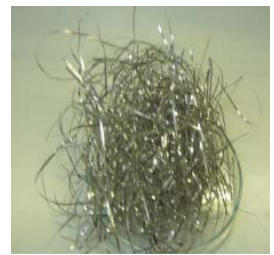

a)

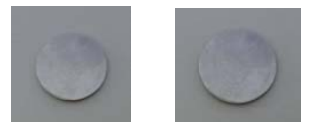

Figure 1 Starting raw material a) and the obtained samples b) SPS and c) IM-CuMC

The sintered samples were homogenized at 1000 ${ }^{\circ} \mathrm{C}$ in vacuum atmosphere for two hours and cooled with the furnace.

The IM-CuMC technique involved the melting of the raw materials in amount according with the chemical composition presented in table 1 using a Heraeus Induction melting furnace in vacuum atmosphere and then poured into a copper mold with the inner space size of $100 \mathrm{x}$ $90 \times 3 / 1.5 \mathrm{~mm}$. The as cast samples were homogenized at $950{ }^{\circ} \mathrm{C}(\mathrm{TT} 1)$ and $1100{ }^{\circ} \mathrm{C}$ (TT2) respectively, for one hour followed by slow cooling to $750{ }^{\circ} \mathrm{C}$ and then fast cooled in ice water.

Slow cooling from $950{ }^{\circ} \mathrm{C}$ and $1100{ }^{\circ} \mathrm{C}$ to 750 ${ }^{\circ} \mathrm{C}$ was achieved by passing an argon stream with a pressure of $<0.5$ bar, (Fig. 1c). The obtained materials were microstructural and mechanical characterized in order to assess their potential for structural applications.

The crystalline structures of the phases present in the synthesized materials were identified by $\mathrm{X}$-ray diffraction using an D8 Advance- Bruker Diffractometer in Bragg-Brentano geometry in 2 $\theta$, equipped with $\mathrm{Cu}$ anode with wavelength $\lambda=$ 1,54 $\AA$, and $\mathrm{Ni} \mathrm{K} \beta$ filter. The X-ray analysis was carried out at room temperature with an increment of 0.05 and a measurement time per step of $4 \mathrm{~s} / \mathrm{step}$. The indexing of the obtained results was done using the EVA analysis software and the ICDD database of the equipment.

The microstructural characterization was performed by scanning electron microscope (SEM) using the Auriga Carl Zeiss equipped with secondary electron detector of In-lens type. The samples for SEM analysis were taken by electroerosion milling with Mo wire and successively polished on Buehler abrasive grains $800,1000,1200,2500,4000$ then polished with alumina suspension in 3 micron and 1 micron at $500 \mathrm{rpm}$ without a clamp, using a LaboPol5 Struers machine.

Determination of the Vickers hardness, Young's mbdulus and elastic contact stiffness (S) was performed by microindentation tests on a MicroCombi Tester (CSM Instruments, Switzerland) equipped with a microindentation module A $(\mathrm{MSST})$ and a Vickers diamond indenter. The tests were performed at room temperature with linear loading from $0.01 \mathrm{~N}$ to $10 \mathrm{~N}$, holding time of $15 \mathrm{~s}$ and approach speed of the indentation of $4 \mu \mathrm{m} / \mathrm{min}$. The calculation method used to determine the values is the Oliver \& Pharr method. The compression tests were made on the cylindrical test samples with $8 \mathrm{~mm}$ in diameter and $12.8 \mathrm{~mm}$ in height using an Instron 3382 testing machine with the maximum applied force of $100 \mathrm{kN}$, a resolution of $0.1 \mathrm{~N}$ and a test speed in the range of $0.1 \ldots 100 \mathrm{~mm} / \mathrm{min}$.

\section{Experimental results and discussions}

XRD characterization

The indexed XRD pattern shown the formation of a multi-phase structure consisting of a majoritary bcc phase of $\alpha$ ferrite type with a constant lattice of $2.86 \AA$ and a secondary phase of zirconium diboride type with hexagonal structure and crystalline parameters, "a" and "c", of $3.16 \AA$ and $3.89 \AA$, respectively (Fig. 2). 
A small amount of residual iron with the crystal parameter of $2.89 \AA$, which is coherent with the $\alpha$ ferrite phase, is present in the sintered materials, at both processing temperatures. Increasing of sintering temperature contributes to the completion of the new formed phases and to the increase of the intensity of diffraction peaks.

Compared with the crystal parameters indexed in the PDF file (for $\mathrm{ZrB}_{2}: \mathrm{a}=3.16 \AA, \mathrm{c}=3.53 \AA$, for $\alpha$ ferrite: $\mathrm{a}=2.87 \AA$ and for residual $\mathrm{Fe}: \mathrm{a}=$ $2.856 \AA$ ), the materials were synthesized with modification, expanding or shrinking the crystal parameters, depending on the type of the formed phase and the sintering process parameters.

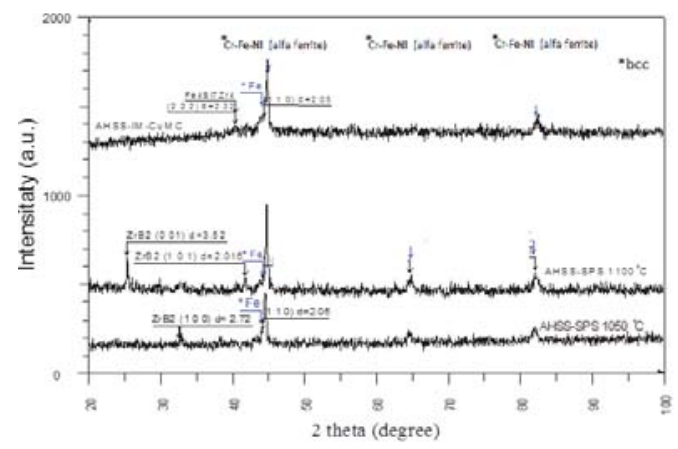

Figure 2. XRD analyses of synthetized AHSS material

In the case of IM-CuMC samples, the X-ray analysis identified a bcc phase of $\alpha$ ferrite type as the majority phase, together with a secondary phase with a tetragonal structure consisting of $\mathrm{Fe}_{4} \mathrm{Si}_{7} \mathrm{Zr}_{4}$ intermetallic compound and residual iron.

\section{Microstructure of the synthetized materials}

Figure 3 shows the electron microscopy images obtained on the synthetized AHSS materials. The SEM images depict different evolution of microstructure depending on the type of processing route. In the case of sintered materials, the microstructure consisted of equiaxed grains of metallic matrix with grain size of $50-60 \mu \mathrm{m}$ in which is relatively homogeneously dispersed a fine precipitated phase with polyhedral shapes and rounded edges of submicronic sizes, highlighted in dark color. (Figure. $3 \mathrm{a}$ and $\mathrm{b}$ )

At the grain boundaries, a reticular phase whose thickness increases with the increase of the sintering temperature was also present. This reticular phase is the result of the fact that the sintering process occurs by persistent liquid phase sintering mechanisms as it was shown by [9]. Boron also acts as sintering aid for ferrous alloys [12]. These precipitates are located within the matrix grains and in the vicinity of the grain boundary, their size being less than $1 \mu \mathrm{m}$.

It is also noticed the presence of a very fine porosity consisting of spherical and triangular pores located inside the grains but also at the grain boundaries.
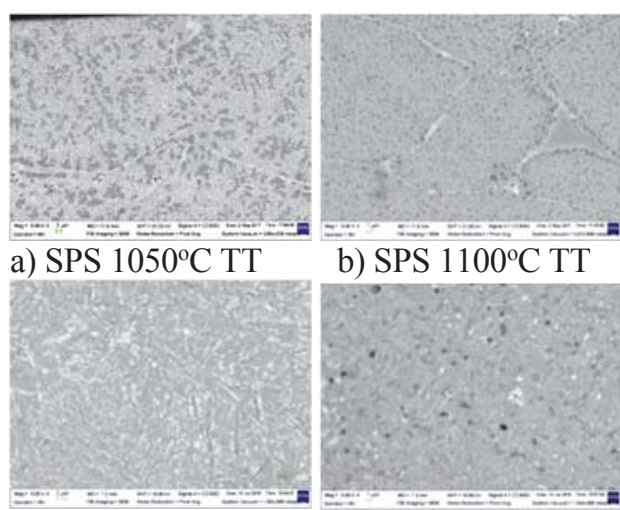

b) SPS $1100^{\circ} \mathrm{C} \mathrm{TT}$

c) IM-CuMC TT 1

d) IM $-\mathrm{CuMC}$ TT 2

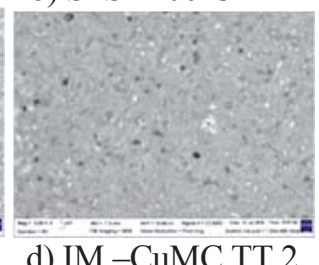

Figure 3. Microstructure of synthesized materials

As the sintering temperature increases, there is a decrease in porosity. The IM-CuMC samples exhibit a different microstructure that changes with the increase of the thermal treatment temperature. At low temperatures, materials have a multiphase type structure consisting of at least two types of grains and a coarse acicular phase, (Figure 3c). With the increase of thermal treatment temperature, the acicular phases are dissolved in the metal matrix. (Figure 3d).

\section{Microindentation tests}

Table 2 shows the values of Vickers hardness, Young's modulus, and elastic contact stiffness obtained from the microindentation tests on the synthetized AHSS materials.

The hardness of the materials in as sintered state decreases with the increase of the sintering temperature, probably due to the increasing of the amount of reticular phase disposed at the grain boundaries. The annealing treatment produced a smooth softening of the materials 
sintered at $1050^{\circ} \mathrm{C}$. A substantially increase in hardness was obtained for the materials sintered at $1100{ }^{\circ} \mathrm{C}$. The Young modulus increases with the increase in the sintering temperature, while their evolution after annealing treatment is different as a function of the temperature at which the materials were processed.

\begin{tabular}{|c|c|c|c|}
\hline Sample code & $\begin{array}{l}\text { Hardness } \\
\text { HV }\end{array}$ & $\begin{array}{l}\text { Young } \\
\text { Modulus } \\
\mathrm{GPa}\end{array}$ & $\begin{array}{l}\text { Elastic } \\
\text { contact } \\
\text { stiffness } \\
\mathrm{N} / \mu \mathrm{m}\end{array}$ \\
\hline SPS 1050 & $571 \pm 54$ & $98 \pm 4$ & $4.58 \pm 0.1$ \\
\hline SPS 1050 - TT & $516 \pm 41$ & $89 \pm 3$ & $4.42 \pm 0.1$ \\
\hline SPS 1100 & $394 \pm 44$ & $127 \pm 7$ & $6.87 \pm 0.1$ \\
\hline SPS 1100 - TT & $486 \pm 43$ & $155 \pm 5$ & $6.55 \pm 0.1$ \\
\hline As cast & $626 \pm 32$ & $185 \pm 6$ & $7.67 \pm 0.1$ \\
\hline Cast, TT1 & $477 \pm 19$ & $166 \pm 8$ & $7.99 \pm 0.3$ \\
\hline Cast,TT2 & $491 \pm 37$ & $171 \pm 9$ & $8.08 \pm 0.1$ \\
\hline
\end{tabular}

Table 2. The values of Vickers hardness, Young's modulus, and elastic contact stiffness of the AHSS sintered materials

From The cast alloys present the higher values of the both mechanical properties: hardness and Young's Modulus. The chosen heat treatment regimes resulted in a decrease of mechanical property values, due to the dissolution of the hardening phases during heating. the point of view of the elastic contact stiffness that is given by the tangent to the unloading curve and is defined as the ratio between the indentation force $(\mathrm{dF})$ and the penetration depth $(\mathrm{dh})$, it can be concluded that the materials undergo significant plastic deformation, no matter what the processing route is (Fig.4).

\section{Compression tests}

Figure 5 show the stress-strain curve of the cast and thermal treated material sample test.

The analysis of the compression-strain curves shows very high values of the mechanical resistance in compression mode test of $2 \mathrm{GPa}$ at a deformation of $30 \%$, indicating a plastic deformation on a large stress level applied to sample test. The curve aspect in the first half indicates that the settlement faces are not parallel planesThese results point to the need to conduct additional research in order to improve the properties of these materials.

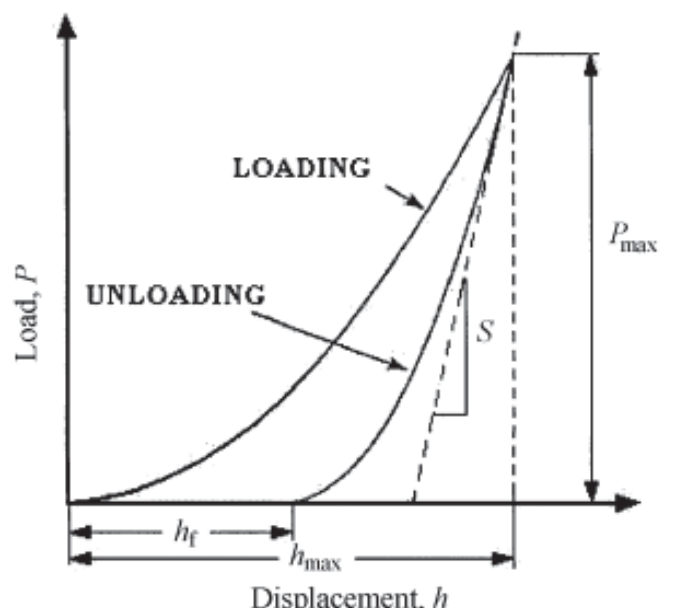

Figure 4. A typical load-displacement curve giving information about elastic contact stiffness

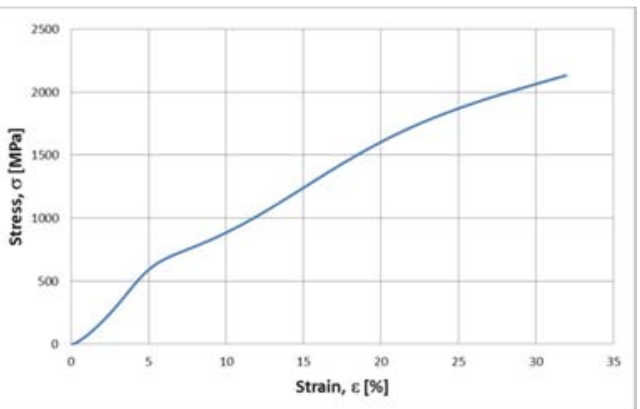

Figure 5. Stress-strain curve obtained on the AHSS sample test.

\section{Conclusions}

AHSS alloys were obtained using spark plasma sintering and induction melting - copper mold casting methods, followed by homogenizing heat treatments.

The main conclusions that can be drawn are:

- The future evolution of materials characteristics depends on the chosen processing route for their synthesis.

- The chosen heat treatment parameters have produced a decrease in mechanical properties due to the fact that the hardening phases dissolved during heating.

- The compression test performed on the cast and thermal treated material samples shows very 
high values of the mechanical resistance of 2 $\mathrm{GPa}$ at a deformation of $30 \%$, indicating a plastic deformation on a large stress level applied to sample test.

- The AHSS alloys presented a very promising compressive strength, which make them suitable for structural applications.

- More approaches are to be performed in order to improve the properties of these materials.

\section{Acknowledgment}

The researches were carried out under the Nucleus Project, No. PN $16 \quad 1102$ 04, (5204/2016).

\section{References}

R. Kuziak, R. Kawalla, S. Waengler, Advanced high strength steels for automotive industry, Archives of Civil and Mechanical Engineering, Vol VIII, No. 2 pp: 103- 117, 2008

Zhu Xiaodong Ma Zhaohui Wang Li, Current Status of Advanced High Strength Steel for Auto-making and its Development in Baosteel, Baosteel Research Institute, China, 2002, pp:18

D.K. Matlock, J. G. Speer, E. De Moor, P. L. Gibbs, Recent developments in advanced high strength sheet steels for automotive applications: An overview, Jestech, 15(1), (2012), 1-12.

D.K. Matlock, J.G. Speer, Processing opportunities for new advanced high-strength sheet steels, Materials and Manufacturing Processes, 25 (2013), 7-13

T. Kulik, Nanocrystallization of metallic glasses, Journal of Non-Crystalline Solids, 287 (2001), 145-161
W. Pilarczyk, R. Nowosielski, A. Januszka, Structure and properties of $\mathrm{Fe}-\mathrm{Cr}-\mathrm{No}-\mathrm{C}$ bulk metallic glasses obtained by die casting method, Journal of Achievements in Materials and Manufacturing Engineering, Vol. 42, Issues 1-2, 2010, 81-87

K.A. Lee, Y.C. Kim, J.H.Kim, C.S. Lee, J. Namkung, M. C. Kim, Mechanical properties of Fe-Ni-Cr-Si-B bulk glassy alloy, Materials Science and Engineering A 449-451 (2007) 181-184

S.J. Zinkle, L. L. Snead, Designing Radiation Resistance in Materials for Fusion Energy, Annual Review of Materials Research 44(1):241-267, August 2014, DOI: 10.1146/annurev-matsci-070813-113627]

T.B. Sercombe, G.B. Schaffer, The sintering of an Fe-Cr-Ni-B-C powder, Materials Science and Engineering A 528 (2010) 751-755

M. K. Mani, G. Viola, M. J Reece, J. P Hall, S.L Evans, Role of Mechanical Pressure during Spark Plasma Sintering of Fe-50Co Alloy on Microstructure and Magnetic Properties, Euro PM2014 - Sinter Steel Mechanical Properties - abstract

M. Lucaci, D. Patroi, V. Tsakiris, M.V. Lungu, E. Manta, A. Iorga, Studies on Fe-Cr-Ni-Si-B Bulk Metallic Glass for Automotive Applications, Advanced Materials Research, ISSN: 1662-8958, Vol. 1114, p. 68-75, July 2015, Trans Tech Publications, Switzerland, DOI:

10.4028/www.scientific.net/AMR.1114.68.

Z-li Liu, X. Chen, Y-xiang Li, K-hua HU, High boron iron-based alloy and its modification, Journal of Iron and Steel Research, International, 2009, 16(3), 37-42, 54 